\title{
A NEW QUANTITATIVE PLANKTON NET
}

\author{
By R. I. Currie and P. Foxton \\ National Institute of Oceanography, Wormley, Surrey
}

(Text-figs. I-6)

\section{INTRODUCTION}

In the study of the production of organic matter in the ocean, it is necessary to find out not only how quickly organic matter is produced, but also how the material is distributed in the various stages of the organic cycle.

Ignoring for the moment difficulties created by the patchiness of plankton distribution, it is possible by taking a suitably sized sample of sea water to obtain a fairly representative sample of small organisms such as the unicellular algae. With the larger organisms constituting the zooplankton, the problem of sampling becomes more complex. Very few of the planktonic animals are small enough or abundant enough to be sampled adequately by a sample of water, and it is necessary to resort to the use of nets, filtering a large quantity of water, to obtain sufficient numbers of organisms. Further complications are introduced by the immense size range of the zooplankton organisms, some of the smaller ones being even smaller than some of the larger phytoplankton, while there is also the fact that some of the larger ones are apparently quite capable of evading capture by their greater powers of swimming.

The present work was aimed at studying the distribution and fluctuations of the biomass of the zooplankton. Although it was realized that no one sampling device could meet all the difficulties involved and give an accurate picture of the zooplankton as a whole, it was hoped that some single means might be found for sampling the bulk organisms of the zooplankton, and thereby collect material from which some valid inferences might be drawn with minor reservations as to the more active forms.

Furthermore, it was hoped to extend this study into both polar and tropical waters, and this also impinged on the method of sampling adopted. It is a well-known fact that organisms filling the same ecological niches are generally of much larger size in cold polar waters than in warmer waters. As an illustration of this, in temperate surface waters an averaged size Chaetognath, say Sagitta enflata, may reach a length of about $20 \mathrm{~mm}$, whereas in the Antarctic the size of a similar creature, Sagitta gazellae, may be about $80-90 \mathrm{~mm}$. This point was rather important if the studies made in these different regions were to be comparable.

As most of the work was designed to take place in oceanic waters, another 
requirement was some form of closing device to enable the different water layers to be sampled.

The final and principal requirement for the investigation was to be able to relate the catch of the net to the actual amount of water from which it was filtered.

It was evident that no existing net could fulfil all of these requirements. The Clarke-Bumpus net (Clarke \& Bumpus, 1950) was probably the nearest answer, but it was obviously too small to cope with the larger organisms, and also suffered the disadvantage of being designed for oblique or horizontal hauls. The practical difficulties of using an oblique net in deep water are rather great, especially as its operation requires so much time. Moreover, a vertical haul has the special advantage that it can conveniently be dovetailed with other work. So far as we are aware no suitable vertical net was in existence to satisfy our requirements, and it appeared to us, therefore, that a new piece of equipment would have to be designed.

From the results of expeditionary work in the past, it is apparent that the vertically hauled Nansen net (Künne, 1929) is a remarkably good sampling device. As it is only $70 \mathrm{~cm}$ diameter at the mouth, it obviously cannot be expected to sample such large and active organisms as Euphausia superba but, nevertheless, towed at a speed of $\mathrm{I} \mathrm{m} / \mathrm{sec}$ ( 2 knots) it is an adequate sampler of the normal bulk organisms of the zooplankton. Furthermore, the net has been used extensively in various parts of the world, and seems to produce reasonably comparable samples from a wide variety of regions.

The main disadvantages of the Nansen net are first, that there is no device to determine how much water it filters and, secondly, even if this were known, the mesh of the net is of two different sizes, namely 40 meshes per linear inch in the forepart of the net and $74 \mathrm{~m}$.p.i. in the after part, and it would be impossible to tell how much water went through each mesh section.

The obvious course seemed to be to adapt the Nansen net so that it would be suitable for quantitative work, but it was clearly advantageous to retain in any altered version as many as possible of the desirable features of the Nansen net.

The first question of mesh size had to be settled experimentally. First, the front French netting section was replaced with canvas and then in consideration of Wiborg's (1948) findings relating to the advantages of certain meshes, various meshes were tried in the filtering part of the net. Eventually a size of 74 m.p.i. throughout was chosen as being the the best compromise between filtering capacity and smallness of organisms taken. The size of aperture of this silk is similar to that of no. 8 standard grade Dufour bolting silk, and in the dry silk averages $200 \mu$ while in the wet silk it shrinks slightly to between $\mathrm{I} 60$ and $\mathrm{I} 80 \mu$.

The next, and most important point, was the measurement of water flow through the net. This was particularly desirable for the deeper hauls where 
there was no indication of the angle at which the net may be hauled up through the different water layers (that is when the drift of the ship causes the wire to stray from the vertical). It was intended that the net would be closed by the Nansen (1915) method, and so it was also desirable that the actual depth of closure might be known. It was evident that to suit the purpose, no available flowmeter existed. What was really required was a meter capable of showing the performance of the net and depth at which it fished. In other words, a meter which could give a graph of the amount of water filtered plotted against depth. The advantages of such a device would be enormous. Any clogging of the net by superabundance of plankton would at once be apparent and the depth at which it occurred would be known. The angle of hauling of the net would not matter since the actual volume filtered between two levels could be determined, and also any irregularity of performance of the net would be obvious.

Even if such a meter were designed, how was it to be fitted in the net? On hydrodynamic considerations it appeared most reasonable to measure the water after it had come through the net. To this end some trials were made. A net was enveloped in a cylindrical canvas sleeve and the meter placed behind the net. This apparatus proved quite unmanageable, as it sank so slowly through the water. The idea had to be abandoned and the meter was then mounted in the mouth of the net where it functioned excellently. The closing problem was later overcome by mounting the meter in a brass drum between a front canvas sleeve and the silk filtering part of the net. The net could then be closed in the normal manner by the Nansen method, in front of the meter.

Some $\mathrm{I} 60$ hauls have been made in all types of weather with this apparatus and so far the results have been extremely satisfactory.

\section{THE DEPTH-FLOWMETER}

The depth-flowmeter is shown in Figs. I and 2. The instrument consists basically of a flowmeter, similar in many of its features to that described by Harvey (1934), in which has been incorporated a depth-recording unit which, like the depth gauges of Hermann (1949) and others, utilizes a Bourdon tube. Flow is measured by the number of revolutions of a smoked glass cylinder which is marked by a stylus, while depth is measured by the vertical displacement of the stylus arm.

Water flowing into the net turns a six-bladed rotor, and through a double worm gear train, giving a I00: I reduction, the rotor drives a slotted metal barrel mounted vertically in a plain bearing. Both the vertical rotor shaft and the horizontal shaft are adjusted to run freely on hardened stainless steel points set in jewel cups. The blades of the rotor are set at an angle of $45^{\circ}$ and the whole is finely balanced. 
The smoked glass cylinders, on which the trace of depth and flow is marked by the phosphor-bronze point of the stylus arm, are a push fit on the metal barrel. The stylus arm is connected through a twin strip flexure system (Geary, 1954) made of beryllium-copper to the free end of the Bourdon tube. The fixed end of the tube, which is sealed with a brass plug, is securely mounted on

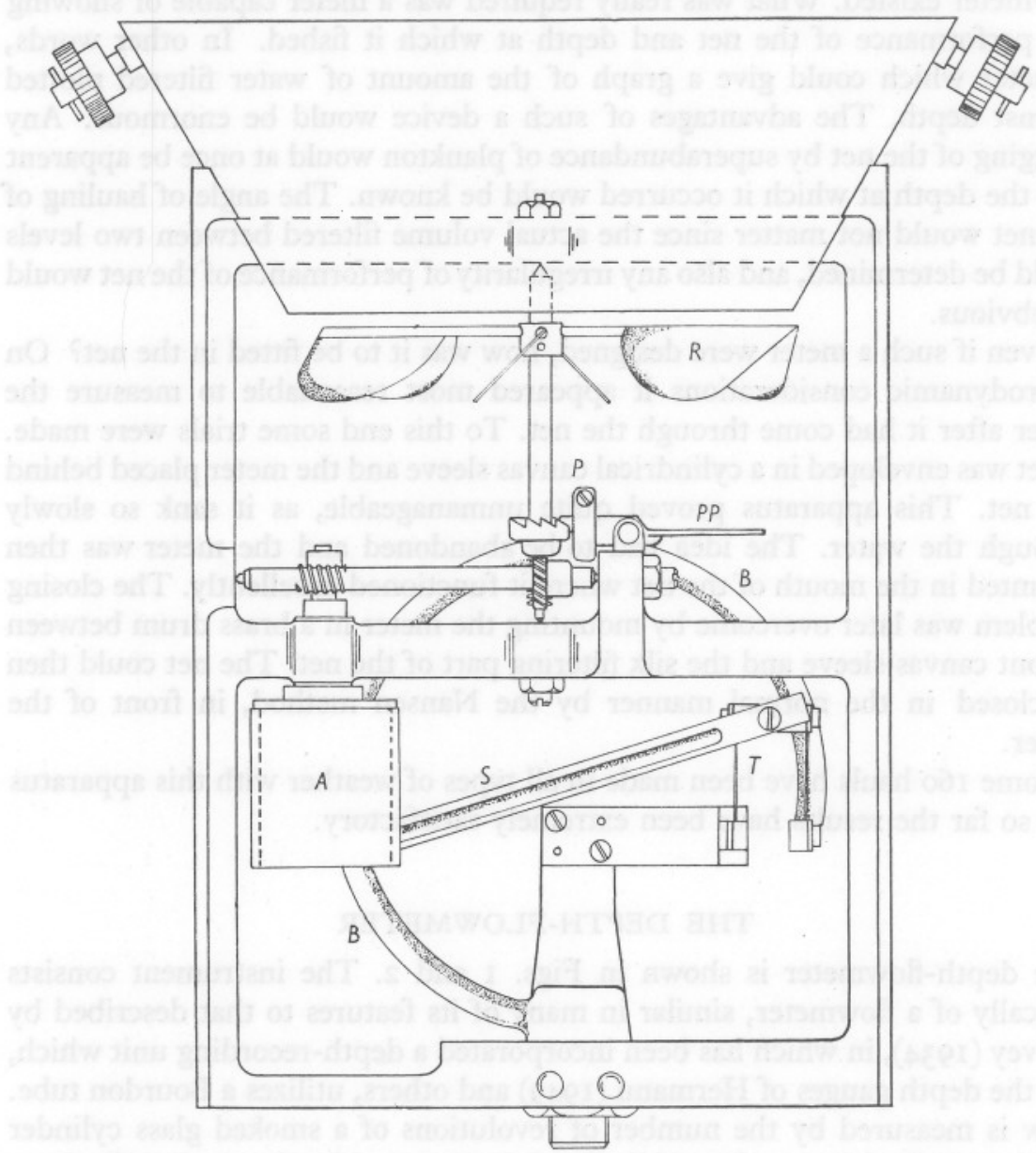

Fig. I. The depth-flowmeter, one half actual size. $A$, smoked glass cylinder; $B$, Bourdon tube; $P$, pawl and ratchet mechanism; $P P$, pawl plate; $R$, rotor blade; $S$, stylus arm; $T$, twin strip flexure system.

the bottom bracket of the cast gun-metal meter frame. The Bourdon tube is sealed at normal atmospheric pressure so that increase of external pressure (with increased depth) causes the arc of the tube to decrease, resulting in a movement of the free end of the tube which produces a displacement of 


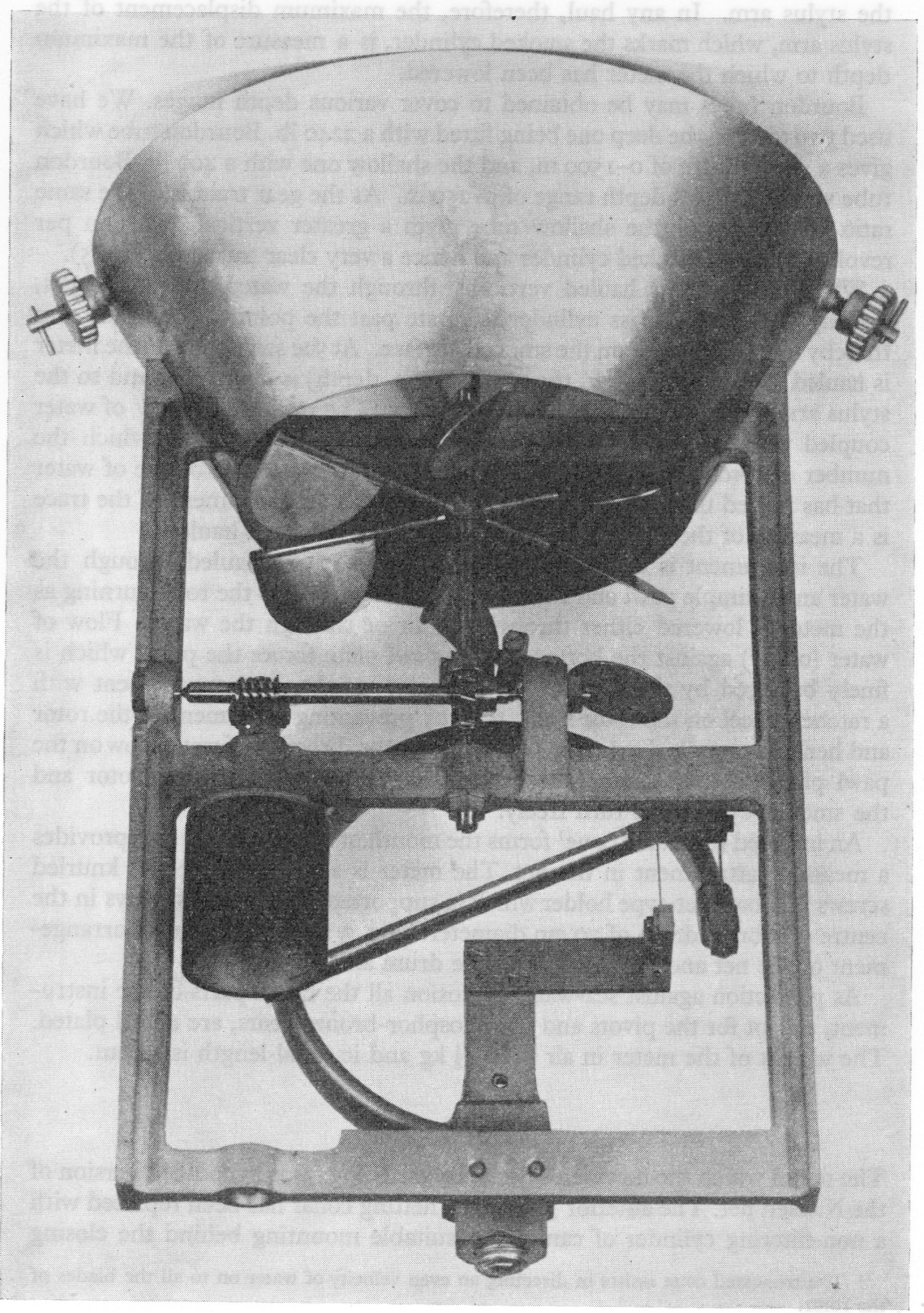

Fig. 2. The depth-flowmeter. 
the stylus arm. In any haul, therefore, the maximum displacement of the stylus arm, which marks the smoked cylinder, is a measure of the maximum depth to which the meter has been lowered.

Bourdon tubes may be obtained to cover various depth ranges. We have used two meters, the deep one being fitted with a $2240 \mathrm{lb}$. Bourdon tube which gives a depth range of $0-1500 \mathrm{~m}$, and the shallow one with a $400 \mathrm{lb}$. Bourdon tube which covers a depth range of $0-250 \mathrm{~m}$. As the gear train is of the same ratio in each meter the shallow tube gives a greater vertical deflexion per revolution of the smoked cylinder and hence a very clear trace (see Fig. 5).

When the meter is hauled vertically through the water the rotor turns, causing the smoked glass cylinder to rotate past the point of the stylus arm thereby marking a trace on the smoked surface. At the same time as the meter is hauled through the water, the pressure (i.e. depth) is decreasing and so the stylus arm moves in an arc along the cylinder. The resultant of flow of water coupled with change in depth thus produces a helical trace in which the number of revolutions of the cylinder is proportional to the volume of water that has flowed through the meter, and the vertical displacement of the trace is a measure of the depth from which the meter has been hauled.

The instrument is designed to operate only as it is hauled through the water and a simple pawl and ratchet mechanism prevents the rotor turning as the meter is lowered either through the air or through the water. Flow of water (or air) against the bottom of the pawl plate forces the pawl, which is finely balanced by the position of a counter-weight, into engagement with a ratchet wheel on the rotor shaft, thereby preventing movement of the rotor and hence the smoked cylinder. On hauling, the direction of water flow on the pawl plate is reversed and the ratchet disengaged, allowing the rotor and the smoked cylinder to turn freely.

An inverted truncated cone ${ }^{1}$ forms the mouth of the meter and also provides a means of attachment in the net. The meter is secured by the two knurled screws in a bayonet-type holder which is supported on three brass stays in the centre of a brass drum of $70 \mathrm{~cm}$ diameter. Fig. 3 shows the general arrangement of the net and the position of the drum and meter.

As protection against sea-water corrosion all the metal parts of the instrument, except for the pivots and the phosphor-bronze gears, are nickel plated. The weight of the meter in air is $c a I_{3}^{1} \mathrm{~kg}$ and its total length is $24 \mathrm{~cm}$.

\section{THE NET}

The net in which the flowmeter has been used (Fig. 3) is a modified version of the Nansen net. The anterior $\frac{1}{4}$ in. mesh netting collar has been replaced with a non-filtering cylinder of canvas. A suitable mounting behind the closing

1 The truncated cone assists in directing an even velocity of water on to all the blades of the rotor. 
point was inserted to take the flowmeter, and the graded mesh of the filtering part of the Nansen net has been restricted to the one mesh throughout.

The flowmeter net has a mouth diameter of $70 \mathrm{~cm}$. Attached to the net ring is a cylindrical tube of canvas $4 \mathrm{ft}$. $(122 \mathrm{~cm})$ in length, around the lower end of which is sewn a piece of log line. This canvas tube slips over a brass drum, $70 \mathrm{~cm}$ diameter and $\mathrm{Ift}(30.5 \mathrm{~cm})$ in length, which carries the flowmeter, and the canvas is held on to the drum by a large metal band with a screw clamp which grips it immediately above the log line.

A similar fixture is provided for the attachment of the filtering part of the net at the lower end of the brass drum. The silk netting is sewn into a 6 in. ( $15 \mathrm{~cm}$ ) wide band of canvas with a log line sewn around the top, and the first silk section is a I m cylindrical length of 74-mesh per linear inch bolting silk. At its after end it joins the second silk section which is a $\mathrm{I} \frac{1}{2} \mathrm{~m}$ length of the same grade of silk tapering conically from a diameter of $70 \mathrm{~cm}$ to a diameter of $8 \mathrm{~cm}$, where it joins a 3 in. $(7 \cdot 5 \mathrm{~cm})$ wide canvas band that forms the attachment to the bucket. The bucket is of the type used with the 'Discovery' net, the N $70 \mathrm{~V}$ (Kemp, Hardy and Mackintosh, 1929).

The net is towed vertically by three bridles which are $\frac{1}{4}$ in. thick brass rods, 32 in. $(8 \mathrm{I} \mathrm{cm})$ long joining together in a ring which fits into the release gear.

Supporting the flowmeter drum, there are three $3 \mathrm{~mm}$ phosphor bronze stays with brass eyes in the ends which are shackled to the net ring and to the flowmeter drum. These stays are seized to three of the six brass rings which are sewn around the anterior canvas collar, about 20 in. $(50 \mathrm{~cm})$ behind the net ring, to carry the throttling rope.

Three further stays of the same wire extend from the flowmeter drum down the whole length of the net. They are joined to the collar above the net bucket, and continue for about $3 \mathrm{ft}$. $(92 \mathrm{~cm}$ ) below the bucket to support the weight. A stout brass ring, 7 in. $(17 \cdot 8 \mathrm{~cm})$ in diameter, encircles the net above the bucket, and is seized on to the three stays, to prevent their twisting.

Fig. 3. The flowmeter net. $A$, canvas fore section encircled by closing rope; $B$, brass drum containing flowmeter; $C$, silk filtering section; $D$, handling line for weight.

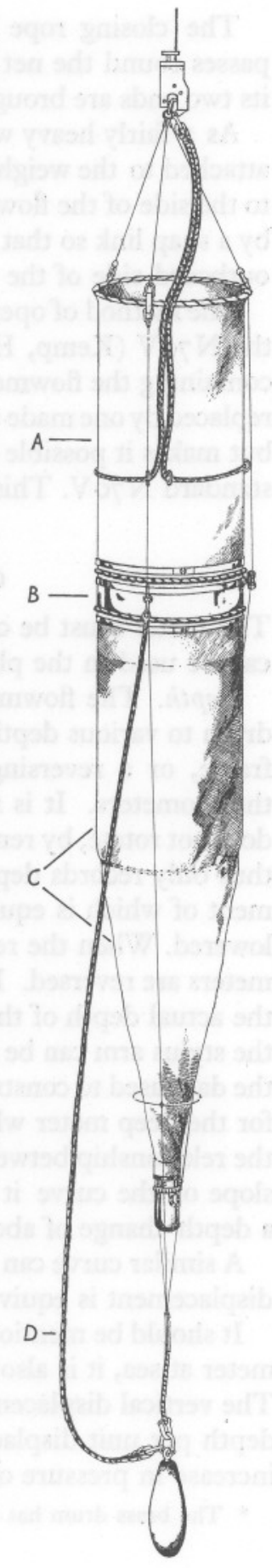


The closing rope is a $16 \frac{1}{2} \mathrm{ft}$. $(5.03 \mathrm{~m})$ length of 2 in. $(5 \mathrm{~cm})$ rope. It passes round the net through the rings on the canvas collar and stay wires; its two ends are brought up and shackled to the closing mechanism.

As a fairly heavy weight (20-40 lb., I0-20 kg) is used, an additional line is attached to the weight to facilitate its handling at the surface. It is shackled to the side of the flowmeter drum. The three stays are attached to the weight by a snap link so that the weight can be detached easily and hooked up on the outboard side of the ship's rail.

The method of operation of this net is similar to that of the 'Discovery' net, the N70V (Kemp, Hardy \& Mackintosh, 1929). Although the brass drum containing the flowmeter is somewhat bulky and heavy and may profitably be replaced by one made of fibre glass, ${ }^{\star}$ it not only affords protection to the meter, but makes it possible to pay out the net much faster than is possible with the standard $\mathrm{N} 70 \mathrm{~V}$. This is a convenient saving of time on very deep hauls.

\section{CALIBRATION OF THE METER}

The meter must be calibrated both for depth and for flow of water before it can be used in the plankton net.

Depth. The flowmeter may be calibrated at sea by lowering it in the brass drum to various depths, having on the wire above it a reversing thermometer frame, or a reversing water-bottle, fitted with protected and unprotected thermometers. It is necessary to immobilize the smoked cylinder so that it does not rotate, by removing either the horizontal shaft or the rotor. The meter thus only records depth, giving a slightly curved trace, the vertical displacement of which is equal to the maximum depth to which the meter has been lowered. When the requisite amount of wire has been paid out, the thermometers are reversed. From the thermometer readings it is possible to calculate the actual depth of the meter and from the trace the vertical displacement of the stylus arm can be measured. The meter is lowered to different depths and the data used to construct a depth calibration curve. Fig. 4 shows such a curve for the deep meter which has been in use since 1954. As would be expected the relationship between depth and stylus displacement is linear, and from the slope of the curve it is seen that I mm stylus displacement is equivalent to a depth change of about $50 \mathrm{~m}$.

A similar curve can be constructed for the shallow meter where I mm stylus displacement is equivalent to $7.5 \mathrm{~m}$.

It should be mentioned that although it has been our practice to calibrate the meter at sea, it is also possible to do the calibration ashore in a pressure tank. The vertical displacement at different pressures gives a curve from which the depth per unit displacement can be calculated using the relationship that an increase in pressure of $\mathrm{I}$ atmosphere is equivalent to an increase in depth of

* The brass drum has since been replaced by one made of anodized aluminium alloy. 
about ro m. Although this is a convenient method it is important to be able to check any calibration from time to time, particularly if any repairs or adjustments have been made to the instrument. Reversing thermometers provide a convenient and accurate method of doing this in the field.

From experiments which have been performed in a pressure tank, it has been found that the accuracy of the depth reading from the flowmeter is limited, not by the accuracy of the Bourdon tubes, but rather by the accuracy with which the trace can be read. Under normal conditions with a clear trace we find this limit is $\pm 0.25 \mathrm{~mm}$, which corresponds to a depth of $\pm 2 \mathrm{~m}$ with the shallow pattern flowmeter and $\pm 15 \mathrm{~m}$ with the deep pattern flowmeter.

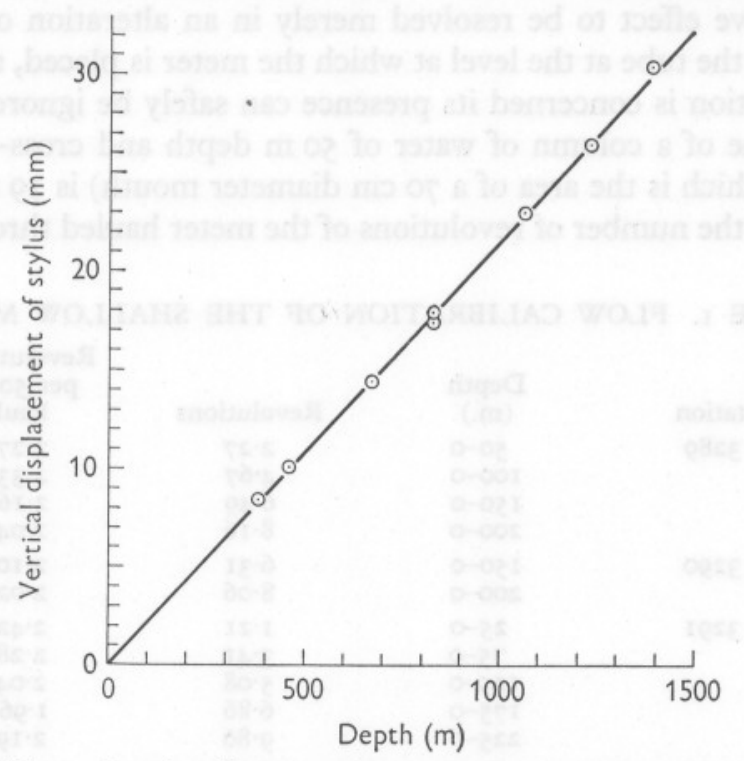

Fig. 4. Depth calibration of the 'deep' pattern flowmeter.

Flow. For similar reasons it is important to be able to calibrate the meter for flow of water at sea. The most practical way of doing this is to haul the meter, fitted in the brass drum with canvas forepart attached-but without the silk filtering section-vertically through a column of water of known length at a constant speed of $\mathrm{I} \mathrm{m} / \mathrm{sec}$. It is then possible to relate the number of revolutions of the smoked cylinder to the flow past the meter of a volume of water equal to the length of the column times the area of the mouth of the net. This assumes that the axial velocity of the water $(\mathrm{Im} / \mathrm{sec})$ is constant across the diameter of the canvas tube. This is not strictly true because the roughness of the walls of the tube (canvas and brass) exerts a drag on the water which results in a loss of velocity near the walls. For a canvas tube whose length is at least 40 times as great as its diameter it can be calculated (Goldstein, I950) that the overall loss in the volume of water passing through the tube may be as 
great as $10 \%$. In the case of the flowmeter net, however, the total length of the canvas tube and the brass drum is only about twice the diameter, and although no definite figure can be given it seems probable that the loss will be less than $2-3 \%$ and that it can safely be ignored. Furthermore, although the meter itself offers little resistance to the passage of water, it undoubtedly must modify the flow pattern to some extent. It is unlikely, however, that this will have a significant effect on the calibration. Both the net hauls and calibration are done with the meter in the same position and so it is only the absolute value of the calibration that the presence of the meter could affect. It is considered, however, that the meter lies sufficiently far behind the mouth of the net, for any obstructive effect to be resolved merely in an alteration of the velocity profile across the tube at the level at which the meter is placed, and that as far as the calibration is concerned its presence can safely be ignored.

The volume of a column of water of $50 \mathrm{~m}$ depth and cross-sectional area of $0.38 \mathrm{~m}^{2}$ (which is the area of a $70 \mathrm{~cm}$ diameter mouth) is $19 \mathrm{~m}^{3}$ and this is equivalent to the number of revolutions of the meter hauled through the same depth.

TABLE I. FLOW CALIBRATION OF THE SHALLOW METER

\begin{tabular}{|c|c|c|c|}
\hline Station & $\begin{array}{c}\text { Depth } \\
\text { (m.) }\end{array}$ & Revolutions & $\begin{array}{c}\text { Revolutions } \\
\text { per } 50 \mathrm{~m} \\
\text { haul }\end{array}$ \\
\hline 3289 & $\begin{array}{r}50-0 \\
100-0 \\
150-0 \\
200-0\end{array}$ & $\begin{array}{l}2.27 \\
4.67 \\
6.49 \\
8.16\end{array}$ & $\begin{array}{l}2 \cdot 27 \\
2 \cdot 33 \\
2 \cdot 16 \\
2 \cdot 04\end{array}$ \\
\hline 3290 & $\begin{array}{l}150-0 \\
200-0\end{array}$ & $\begin{array}{l}6 \cdot 3 I \\
8 \cdot 06\end{array}$ & $\begin{array}{l}2 \cdot 10 \\
2 \cdot 02\end{array}$ \\
\hline 3291 & $\begin{array}{r}25-0 \\
75-0 \\
125-0 \\
175-0 \\
225-0\end{array}$ & $\begin{array}{l}I \cdot 2 I \\
3 \cdot 4 I \\
5 \cdot 08 \\
6.86 \\
9 \cdot 86\end{array}$ & $\begin{array}{l}2 \cdot 42 \\
2 \cdot 28 \\
2 \cdot 04 \\
1 \cdot 96 \\
2 \cdot 19\end{array}$ \\
\hline 3292 & $\begin{array}{r}50-0 \\
100-0\end{array}$ & $\begin{array}{l}2 \cdot 16 \\
4 \cdot 06\end{array}$ & $\begin{array}{l}2 \cdot 16 \\
2 \cdot 03\end{array}$ \\
\hline
\end{tabular}

The results of thirteen calibration hauls made with the shallow meter are given in Table $\mathrm{I}$. The result of each haul has been expressed as the number of revolutions per standard haul of $50 \mathrm{~m}$, and the calibration value is taken as the mean number of revolutions per $50 \mathrm{~m}$ haul. It is seen from Table $\mathrm{I}$ that the mean revolutions per $50 \mathrm{~m}$ haul is 2.15 ; which is equivalent to a flow of $19 \mathrm{~m}^{3}$ of water.

\section{THE PREPARATION OF THE SMOKED CYLINDERS AND TREATMENT OF THE TRACES}

The glass cylinders on which the trace is recorded are made from precisionbored glass tubing of $28 \mathrm{~mm}$ bore, $2 \mathrm{~mm}$ wall thickness and $35 \mathrm{~mm}$ length. These cylinders cost about Is. each but they can be used time and time again. 
The problem of storing many smoked cylinders, as is the practice with bathythermograph slides, makes it more convenient to smoke the requisite number of cylinders just prior to use. The method is basically the same as that used for bathythermograph slides except that the cylinder is rotated in the smoky flame, and the deposit of carbon is made rather heavy. The procedure will be described in detail because it is essential to have a uniform deposit of soot which will not wash off as the meter is hauled through the water.

(I) If the cylinder has been used before, it is washed first in acetone to remove the cellulose varnish (see below) and secondly in carbon tetrachloride and then dried with a clean rag.

(2) A very thin even film of tallow (vaseline or petroleum jelly will also do) is applied to the outer surface of the cylinder.

(3) The cylinder is rotated at about $30 \mathrm{rev} / \mathrm{min}$ in the smoky part of a spirit flame, the spirit lamp being filled with a $15 \%$ solution of cellulose thinner in methylated spirit. A cylinder-holder geared to a small electric motor has proved particularly suitable for rotating the glass cylinder.

(4) Smoking is continued until the deposit is a fairly dense even black, which gives the best trace for photographic reproduction.

(5) After use the trace is preserved by first washing the cylinder in tap water, drying it, and then dipping it in clear cellulose varnish and drying again.

For ease of storage and also to facilitate the measurement of the flow and depth, a photographic record is then made of the trace. This is simply and quickly done by wrapping a piece of bromide photographic paper round the cylinder which is then illuminated from the inside. Even illumination is ensured by slipping the cylinder over a piece of Perspex rod which is slightly roughened on its surface. A torch bulb shines into the highly polished end of the rod. The resulting photograph, which is a reverse image of the trace, can be analysed and stored as a record of the haul, and the cylinder can be used again.

\section{DESCRIPTION OF THE TRACES}

The prototype flowmeter was first taken to sea in September 1954, and it gave most encouraging results. Only minor modifications were necessary, principally to improve the method of attachment of the meter inside the net, and since then it has been used successfully on four short cruises of the R.R.S. Discovery II. In all, about 160 hauls have been made, of which only three have yielded traces which were unreadable. The only major repair which has been necessary was the replacement of two jewelled cup bearings.

It has already been noted that the spiral traces obtained on the smoked-glass cylinders are photographed on to a piece of bromide paper wrapped round the outside of the cylinder. Fig. 5 shows a typical series of these photographic records of the traces. It will be clear from the manner in which they are made 
that the oblique lines in those figures represent one long continuous spiral. The traces which are shown for the 50-0, 100-50 and 200-100 m hauls were made with the shallow flowmeter, while those for the 500-200 and 1000-500 m were made with the deep pattern of flowmeter.

To understand the significance of the traces, let us first consider the one representing the 200-100 $\mathrm{m}$ haul at station $33 \mathrm{I2}$ (Fig. 5). The top of the trace represents the sea surface, and descending across the trace there is a gently

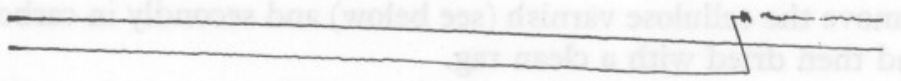

$50-0 \mathrm{~m}$

$100-50 m$

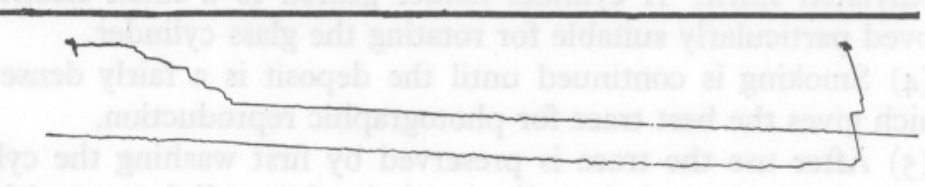

$200-100 m$
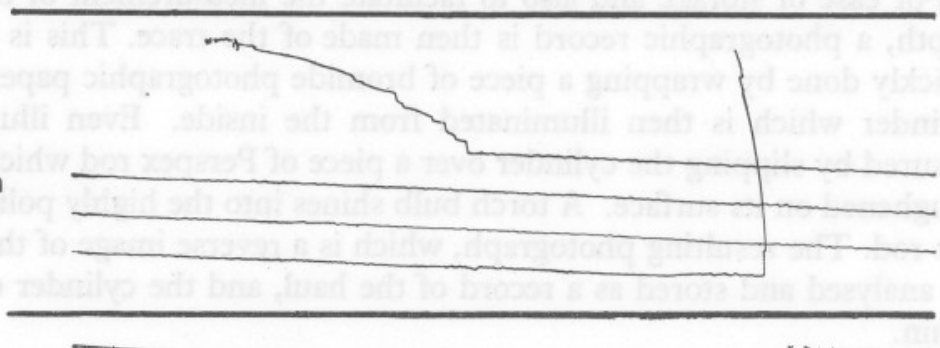

$500-200 m$

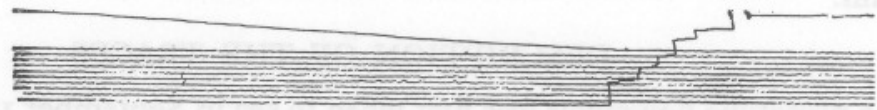

$500-200 \mathrm{~m}$

$1000-500 \mathrm{~m}$

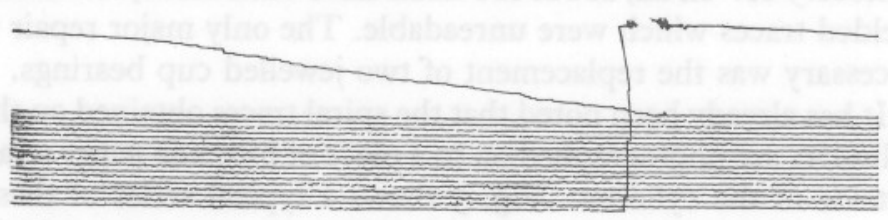

Fig. 5. Flowmeter traces, from hauls made at station 3312. $\times 0.86$. 
curved vertical line. This is the arc made by the stylus as the net was paid out. At this station the weather was very calm, and the net apparently went straight down without any surging which would be reflected in a rotation of the glass cylinder. From the lowest point of the trace, hauling was started, and the gently rising oblique line is formed as the glass cylinder is slowly turned by the rotor and the stylus rises with the decreasing pressure. In this particular trace, three complete rotations of the glass cylinder took place, and part way through the fourth revolution the net was closed and filtration stopped. The trace then rises upwards to begin with and then moves over to the left slightly as the closed net comes up to the surface. Theoretically the trace should have gone straight up to the surface after closure. This small amount of 'apparent filtration' which occurs after the net is closed is probably the result of a slight percolation of water through the canvas which is closing the net above the flowmeter. There must be quite a considerable pressure on this canvas as the closed net is hauled upwards, and no doubt a small amount of water is forced through the weave of the canvas.

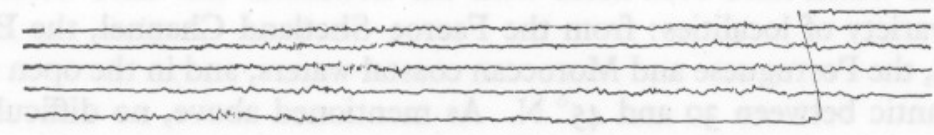

Fig. 6. Flowmeter trace from roo-0 $\mathrm{m}$ haul at station 3290 , showing the effect of stray on the wire in the latter part of the haul.

From this explanation it will be easy to see what the other traces in Fig. 5 represent. The spiral trace made by the deep pattern flowmeter is of course much closer than that of the shallow version, since the vertical displacement of the stylus per unit of depth is not so great, but it is still quite clear to read. On most occasions it will be seen that there appears to be a certain amount of filtration when the net is lowered down. This is clearly seen, for example, in the 500-200 m trace in Fig. 5. Instead of the straight descending line as in the $200-100 \mathrm{~m}$ trace, there is a step-ladder effect on the 500-200 $\mathrm{m}$ trace. This is probably caused by water surging in and out of the mouth of the net since the rate of lowering cannot be adjusted to the movements of the ship. The authors observed this taking place under water and photographed it in the course of making a film of the closing of the Nansen net. It is unlikely that the net actually filters any appreciable quantity of water as it makes these surges, and if it did, anything it caught would be promptly washed out again.

A certain amount of short-period vibration can be seen in the traces, and this is probably caused by vibration of the stylus arm as the water flows over it.

So far, the hauls with the flowmeter net have been made on board the R.R.S. Discovery II, a ship which normally works stations hove to, into the wind. Consequently, the wire to the net is usually fairly near the vertical, all 
the time. At one or two stations, however, the ship has fallen off the wind in the middle of a haul with the result that the wire to the net has acquired a considerable angle of stray, and an examination of the traces from the flowmeter on these occasions has shown that the stray is reflected in the amount of water filtered by the net. In the I00-0 $\mathrm{m}$ haul at station 3290 a close inspection of the flowmeter trace (Fig. 6) shows that the spacing of the oblique lines becomes less nearer the surface. In other words, the amount of water filtered per unit depth near the surface was greater than the amount filtered per unit of depth, earlier in the haul. During this haul the wire took on a stray partway through the haul. Obviously on such occasions the net is towed through the water as well as being hauled, and it filters more water per unit depth than it would in a truly vertical haul.

So far no traces have given any indication of reduction of filtration on account of clogging of the net by phytoplankton.

\section{DISCUSSION}

The hauls which have been made with the flowmeter net have come from a wide variety of localities: from the Faeroe-Shetland Channel, the English Channel, the Portuguese and Moroccan coastal waters, and in the open northeast Atlantic between 30 and $45^{\circ} \mathrm{N}$. As mentioned above, no difficulty has been experienced with the net clogging, although many hauls have been made in waters visibly discoloured by the density of the phytoplankton, and also in areas of dense salp concentrations.

With the entire assembly of net and meter the measured flow of water, as indicated by the number of revolutions of the smoked cylinder, has been found to be only slightly less than the flow observed when the meter is hauled in the brass drum without the net attached, i.e. as in the calibration hauls (see p. 25). For instance the mean revolutions per $50 \mathrm{~m}$ haul for twelve shallow hauls with the complete net was found to be $\mathrm{I} \cdot 96$ compared with 2.15 given by the results in Table I. This difference in flow represents that part of the theoretical column of water that is prevented from flowing into the apparatus by the back pressure created by the presence of the silk netting, and can thus be used as a measure of the filtering efficiency of the net. Using the values quoted above we find that the filtration coefficient of the net when hauled at $\mathrm{I} \mathrm{m} / \mathrm{sec}$ has the surprisingly high value of about $90 \%$. This is, of course, on the fairly reasonable assumption that the presence of the net does not appreciably alter the pattern of flow that pertains in the drum during the calibration (i.e. when the net is absent). One point which no doubt contributes towards the high filtration coefficient is that the total length of the silk part of the net is $2 \frac{1}{2} \mathrm{~m}$, and as the first section is cylindrical the net has a very high ratio of filtering surface to mouth area.

As the filtration coefficient of the net is so high there will be little or no frontal wave preceding the net; this fact must add to the ability of the net to 
capture more active organisms: undoubtedly there will be less warning of approach of the net to them. The hauls which have been examined appear to take a very good representative sample of the bulk of the zooplankton. For a vertical net, the samples are relatively large, and this, of course, is clearly an advantage in attaining a reasonable degree of accuracy in their subsequent treatment.

The main advantage of the net, however, is its ability to sample different water layers in a quantitative manner. That this is essential in the study of the standing crop in the ocean is borne out by Foxton's (1956) results. These show that the extent of the seasonal change in the standing crop of zooplankton in the Antarctic could not have been properly understood without having divided hauls to a depth of at least $750 \mathrm{~m}$ available. Recent observations with the flowmeter net also bear out the fact that a large part of the standing crop is to be found in deep water. As an example, at station 3216 (April 1955) in the Faeroe-Shetland Channel, in a depth of $900 \mathrm{~m}$, about $40 \%$ of the standing crop lay below $250 \mathrm{~m}$ and about $25 \%$ below $500 \mathrm{~m}$. It would be possible to quote many more observations in subtropical waters where a similar distribution holds good.

The flowmeter itself may well find more extensive applications. Besides its adaptability to other vertical nets, it may be possible to use the meter on obliquely hauled nets. In this case it would probably only be possible to use the 'shallow pattern', as the spiral trace produced by an oblique tow of the 'deep pattern' meter would no doubt be too compressed to be interpreted accurately. The meter is also a useful tool for determining the filtration coefficients of other nets.

We should like to express our thanks to $\mathrm{Mr} \mathrm{R}$. Dobson, who was entirely responsible for producing the design of a working instrument from our inadequate sketches of the flowmeter. The meters were manufactured in the workshop of the National Institute of Oceanography. Mr R. Burt of R.R.S. Discovery $I I$ carried out all the rigging of the net and contributed many helpful practical ideas. $\mathrm{Mr} \mathrm{H}$. Charnock gave us guidance on matters concerning the water flow of the net. We are indebted to Mr P. M. David for the photograph of the depth-flowmeter in fig. 2, and also to $\mathrm{Mr} \mathrm{A}$. Style for the perspective drawing of the net in Fig. 3 .

\section{SUMMARY}

The apparatus described in this paper was constructed for the purpose of sampling the zooplankton standing crop in the ocean in a quantitative manner.

A meter is described, which will record both the depth and amount of water which a net filters as it is hauled vertically through the water. The meter records on a smoked glass cylinder. 
The meter is mounted in a brass drum which is positioned in front of the silk filtering section of the net. In front of the meter a long canvas sleeve carries the throttling rope which closes the net by the Nansen method.

Calibration of the meter for depth is done by using reversing thermometers and lowering to a series of suitable depths. Flow calibration is easily accomplished in the field by towing the canvas sleeve and meter without the silk net.

The method of smoking the glass cylinders and taking photographic records of them is described.

From the records it is possible to study the complete behaviour of the net below water-what depth range it has fished, how much clogging occurred, the depth of closure, etc.

\section{REFERENCES}

Clarke, G. L. \& Bumpus, D. F., 1950. The plankton sampler-an instrument for quantitative plankton investigations. Amer. Soc. Limnol. Oceanogr., Special Publication, no. 5.8 pp.

FoxToN, P., 1956. The distribution of the standing crop of zooplankton in the Southern ocean. 'Discovery' Rep., Vol. 28, pp. I91-236.

Geary, P. J., 1954. Flexure Devices. Pivots. Movements. Suspensions. British Scientific Instrument Research Assoc., Res. Rep., M. I8.

Goldstern, S., I950. Modern Developments in Fluid Dynamics. 2 vols. London: Oxford University Press.

Harvey, H. W., I934. Measurement of phytoplankton population. F. mar. biol. Ass. U.K., Vol. 19, pp. 76I-74.

HermanN, F., I949. A recording depth gauge for use in horizontal hauls with stramin nets and other pelagic fishing implements. Medd. Komm. Havundersøg., Kbh., Ser. Fisk., Bd. II, No. 5.

Kemp, S., HaRdy, A. C. \& Mackintosh, N. A., I929. Discovery Investigations: Objects, equipment and methods. 'Discovery' Rep., Vol. I, pp. I4I-232.

KÜNNE, CL., I929. Vergleich der Fangfähigkeit verschiedener Modelle von planktonNetzen. Rapp. Cons. Explor. Mer, Vol. 59.

NANSEn, F., 1915. Closing nets for vertical hauls and for horizontal towing. Publ. Circ. Cons. Explor. Mer, No. 67.

WiBORG, K. F., I948. Experiments with the Clarke-Bumpus plankton sampler and with a plankton pump in the Lofoten area in northern Norway. Fiskeridir. Skr. Havundersøk., Bd. 2, No. 2. 